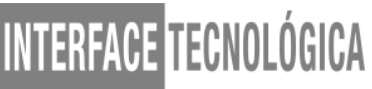

\section{ESTUDO DE VIABILIDADE DA IMPLANTAÇÃO DE UMA PEQUENA AGROINDÚSTRIA NO SETOR DE DOCES EM TAQUARITINGA/SP}

\author{
FEASIBILITY STUDY OF IMPLEMENTATION OF A SMALL AGROINDUSTRY IN \\ THE SWEET SECTOR IN TAQUARITINGA/SP
}

\author{
Jeisse Kelle Melo Santana - jeisse_melo@hotmail.com \\ Marcos Alberto Claudio Pandolfi - marcos.pandolfi@fatectq.edu.br
}

Faculdade de Tecnologia de Taquaritinga (Fatec) - Taquaritinga - São Paulo - Brasil

DOI: 10.31510/infa.v17i1.736

\begin{abstract}
RESUMO
O processo de industrialização de alimentos tem como o objetivo promover a conservação dos produtos para ofertá-los durante todo o ano, bem como agregar valor à matéria-prima. A forma mais comum de industrializar as frutas é produzindo doces e geleias. O presente projeto tem como principal objetivo analisar a viabilidade de implantação de uma agroindústria de doces, na cidade de Taquaritinga-SP para a venda no município e aos redores, sendo um produto que poderá ser vendido diretamente para o consumidor final e comércio local da região. Foram feitas análises de investimentos, equipamentos, despesas, custos fixos, custos variáveis, estimativas de vendas e receita, para analisar a viabilidade econômica do presente projeto. O trabalho foi desenvolvido por meio de desenvolvimento de um plano de negócio para a instalação de uma pequena indústria no setor de doces, exclusivamente em potes, fazendo o uso de pesquisas bibliográficas, pesquisa de mercado pela região de instalação da pequena agroindústria e um estudo de viabilidade econômica. A estimativa de produção e receitas foram feitas a partir do valor final de tonelada de cada fruta e utilizamos uma porcentagem específica de lucro para cada doce. Tendo como resultado o VPL de R\$ $288.116,41$ reais, a TIR de $55 \%$ e a TMA de $(12 \%)$.
\end{abstract}

Palavras-chave: Agroindústria. Doces. Implantação. Viabilidade.

\begin{abstract}
The process of food industrialization aims to promote the conservation of products to offer them throughout the year, as well as adding value to the raw material. The most common way to industrialize fruits is by producing sweets and jellies. The main objective of this project is to analyze the feasibility of implementing an agroindustry of sweets in the city of Taquaritinga-SP for sale in the municipality and to the surrounding areas. Analysis of investments, equipment, expenses, fixed costs, variable costs, sales and revenue estimates were made to analyze the economic viability of this project. The work was developed through the development of a business plan for the installation of a small industry in the sweets sector, exclusively in pots, making use of bibliographic research, market research by the region of installation of the small agroindustry and an economic feasibility study. The estimate of production and revenues was made from the final value of a ton of each fruit and we used a
\end{abstract}




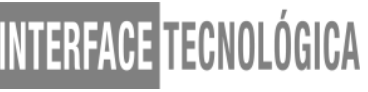

specific percentage of profit for each jam. The result was a VPL of R $\$ 288,116.41$, an TIR of $55 \%$ and an TMA of (12\%).

Keywords: Agroindustry. Sweets. Implantation. Viability.

\section{INTRODUÇÃO}

A agroindústria é o setor que processa as matérias-primas agropecuárias, com a finalidade de agregar valor ao produto, transformando-o em produto elaborado. A agroindústria é uma atividade de elevada importância para o país, tanto no nível social quanto no econômico (TORREZAN, 2015).

O processo de agro industrialização de doces tem como objetivo promover a conservação dos produtos para oferecê-los ao decorrer do ano, como a agregação à matériaprima (SENAR, 2017).

A transformação da matéria-prima evita o desperdício, amplia o prazo para o consumo e proporciona um melhor padrão alimentar e mantém as características como: sabor, aroma, e valores nutricionais. A forma mais comum de agro industrializar as frutas é produzindo doces, geleias e compotas (SENAR, 2017).

\footnotetext{
Para obtenção de um doce, é preciso combinar bem os seguintes elementos: fruta, pectina, açúcar e ácido. As frutas contribuem com o sabor, aroma e cor. A pectina é a substância que dá a consistência gelatinosa. O açúcar, além de adoçar, contribui para a formação do gel. $\mathrm{O}$ ácido tem por finalidade promover o nível de acidez necessária para que ocorra a geleificação, realçando o aroma natural da fruta (TORREZAN, 2015, página 9).
}

A qualidade do doce é determinada pela qualidade da matéria-prima utilizada. Sendo que as frutas utilizadas devem estar necessariamente sadias e conservadas, sem nenhum vestígio de predadores. Frutas exclusivamente muito verde, ou com alguma característica de podridão, insetos e larvas devem ser descartadas, como também alguns resíduos indesejados folhas, caules, pedregulhos entre outros (TORREZAN, 2015).

Mas antes de produzir e vender doces, é necessário fazer planejamento, sendo fundamental a pesquisa de mercado, pesquisa de consumidores, pesquisa de concorrência e ainda, pesquisar a demanda, as técnicas de produção mais modernas, os custos e possibilidades de lucro (GONÇALVES, 2013).

O empreendimento da agroindústria de doces será instalado no município de Taquaritinga, situada em um terreno de $360 \mathrm{~m}^{2}$, localizado na zona industrial do município. O 


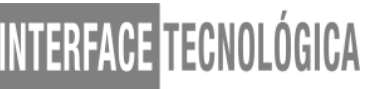

presente projeto tem como principal objetivo propor a instalação de uma agroindústria de doces de banana, goiaba, abobora, mamão e de batata-doce - todos em potes, na cidade de Taquaritinga-SP para a venda no município e aos redores, sendo um produto que poderá ser vendido diretamente para o consumidor final, mas também em alguns estabelecimentos da região.

\section{FUNDAMENTAÇÃO TEÓRICA}

Segundo o Serviço Brasileiro de Apoio às Micro e Pequenas Empresas (SEBRAE), o mercado de doces tem expandido cada vez mais, apesar de sofrer ataques contínuos de diversos profissionais da área da saúde como nutricionistas e endocrinologistas, as confeitarias e lojas de doces crescem em larga escala, assim como surgem novos fabricantes de doces em compotas.

O aumento do consumo de doces vem seguindo novos rumos, com um paladar mais refinado, o apreço pelas inovações faz com que seja cada vez mais valorizada a qualidade dos ingredientes (SEBRAE, 2019).

De acordo com a Associação Brasileira da Indústria de Alimentos (ABIA), o setor de alimentos no Brasil avançou 2,8\% em receita no ano de 2018, registrando $\mathrm{R} \$ 656$ bilhões, incluindo exportações e vendas para o mercado interno, representando 9,6\% do PIB. De acordo com a pesquisa, os dados apontam que o setor criou mais de 13 mil postos de trabalho no mesmo período. A soma dos investimentos em ativos, fusões e aquisições avançaram para $\mathrm{R} \$ 21,4$ bilhões, contribuindo para o crescimento de 13,4\% frente a $\mathrm{R} \$ 18,9$ bilhões atingidos no ano de 2017 (ABIA, 2017).

O setor de doces enfrenta diversos tipos de concorrências, pois o comércio de produtos de doces e outros semelhantes é de prática de vários estabelecimentos, como na região de instalação há pequenas e médias empresa no mercado local (FILIPIN, 2015).

\subsection{Análise e dimensionamento de mercado}

Uma análise de mercado é a definição do mercado concorrente, ou seja, é o alvo do negócio, consiste em criar o perfil dos consumidores que deseja alcançar, aqueles clientes prédefinidos. Além disso, uma análise de mercado apresenta os maiores benefícios oferecidos 


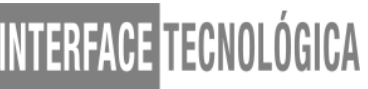

pelo produto e uma previsão de vendas, onde é recomendável apresentá-la em diferentes cenários, sendo estes o cenário mais provável, o otimista e o cenário pessimista (LONGENECKER et al., 2011).

Para Biagio e Batocchio (2012), a análise de mercado além de fornecer subsídios para o plano de marketing tem como objetivo se relacionar com o conhecimento que a empresa possui do seu ambiente externo, destacando quais seriam suas ameaças.

A análise de mercado é um modo de conhecer o mercado, avaliando o ambiente onde o produto ou serviço será lançado, destaca Biagio e Batocchio (2012).

\subsection{Processos e capacidade produtiva}

O processo industrial para a fabricação dos doces é praticamente a mesma para todos os tipos de matéria prima que a empresa atual, que são: banana, batata-doce, goiaba, abobora e mamão. Um fluxograma contendo as operações básicas e gerais para frutas é apresentado na Figura 1.

\section{Figura 1 - Fluxograma do processo de fabricação dos doces.}

\section{MATERIA PRIMA \\ CONCENTRAÇÃO}

\section{VERIFICAÇÃO DO \\ PONTO}

\section{RESFRIAMENTO}

Fonte: Elaborada pelos autores (2019)

Ressalta-se que, além das etapas básicas ilustradas na Figura 1, outras específicas de cada fruta / variedade são implementadas de acordo com a necessidade.

A capacidade produtiva de fabricação dos doces será de $700 \mathrm{~kg}$ de frutas por dia. Sendo $200 \mathrm{~kg}$ da fruta goiaba, $100 \mathrm{~kg}$ de batata-doce, $150 \mathrm{~kg}$ da fruta banana, $150 \mathrm{~kg}$ de abobora e $100 \mathrm{~kg}$ de mamão sendo considerados diários, de acordo com a Tabela 1: 


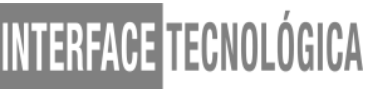

A Tabela 1 apresenta os volumes propostos de cada fruta a serem processados diariamente, visando um melhor aproveitamento da planta.

Tabela 1 - Capacidade das Frutas

CAPACIDADE PRODUTIVA DE FRUTAS

\begin{tabular}{c|c|c|c}
\hline Frutas & Quantidade Diária kg & $\begin{array}{c}\text { Quantidade Semanal } \\
\mathrm{kg}\end{array}$ & $\begin{array}{c}\text { Quantidade Mensal } \\
\mathrm{kg}\end{array}$ \\
\hline Goiaba & 200 & 1200 & 4800 \\
\hline Batata-Doce & 100 & 600 & 2400 \\
\hline Banana & 150 & 900 & 3600 \\
\hline Abobora & 150 & 900 & 3600 \\
\hline Mamão & 100 & 600 & 2400 \\
\hline & & & $\mathbf{1 6 8 0 0}$ \\
\hline TOTAL & $\mathbf{7 0 0}$ & $\mathbf{4 2 0 0}$ & \\
\hline
\end{tabular}

Fontes: Elaborada pelos autores (2019)

Importante ressaltar que os volumes previstos na Tabela 1 podem sofrer variações de acordo com a demanda de doces e oferta de matéria-prima ao longo do ano.

Suportando uma capacidade de 4.200 potes de 500 gramas de doces variados por semana, sendo um total de $8.400 \mathrm{~kg}$ de fruta semanal, considerando que uma semana de trabalho tenha 6 dias, sendo segunda a sábado.

A capacidade produtiva da fábrica foi definida a partir do porte da empresa, como está entrando agora no mercado, será apenas uma máquina para cada função, ou seja, uma máquina de embalagem, uma máquina de esteira com lavagem das frutas, um tacho para a preparação dos doces e uma bancada de resfriamento.

\section{PROCEDIMENTOS METODOLÓGICOS}

O trabalho foi desenvolvido por meio de desenvolvimento de um plano de negócio para a instalação de uma pequena indústria no setor de doces, exclusivamente em potes, fazendo o uso de pesquisas bibliográficas, pesquisa de mercado pela região de instalação da pequena agroindústria e um estudo de viabilidade econômica. A pesquisa de mercado ocorreu na cidade de instalação onde foi feito o levantamento dos doces mais consumidos na cidade. 


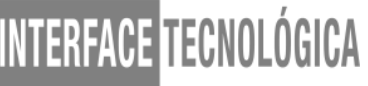

Esses levantamentos foram feitos durante o ano de 2019, levando em consideração dados históricos e artigos publicados.

Os procedimentos adotados para o desenvolvimento do presente projeto foram leituras de capítulos de artigos científicos, capítulos de livros e a realização de tabelas para o cálculo dos valores reais, assim como a elaboração de um plano de negócio e análise da viabilidade econômica.

\section{RESULTADOS E DISCUSSÃO}

O presente trabalho consiste na instalação da agroindústria em um terreno pequeno no setor industrial da região de Taquaritinga-SP, com uma metragem de $360 \mathrm{~m}^{2}$ no valor de R\$ 95.000,00 reais, alvenaria do barracão da agroindústria será de $100 \mathrm{~m}^{2}$, sendo que a cada $1 \mathrm{~m}^{2}$ de construção de uma agroindústria equivale a R \$2.000,00 reais. As obras civis para os 100 $\mathrm{m}^{2}$ equivale ao orçamento feito pela Pontual Serviços de Construção LTDA da cidade de Matão - SP. Coordenando também o Projeto Técnico de Legalização da Atividade da Agroindústria, sendo R $\$ 9.034,00$ reais, além de um veículo utilitário usado, conforme apresentado na Tabela 2.

Tabela 2 - Investimentos

\begin{tabular}{c|c|c|r|r}
\hline \multicolumn{7}{|c}{ TERRENO / ÁREA / OBRAS CIVIS / ESTRUTURA FÍSICA } \\
\hline Item & Quant & Descriçao & Valor Unit & \multicolumn{1}{c}{ Valor total } \\
\hline 1 & 1 & Terreno $360 \mathrm{~m}^{2}$ & $95.000,00$ & $95.000,00$ \\
\hline 2 & 1 & Alvenaria & $200.000,00$ & $200.000,00$ \\
\hline 3 & 1 & Obras Civis & $28.000,00$ & $28.000,00$ \\
\hline 4 & 1 & Projeto técnico de legalização da atividade & $9.034,00$ & $9.034,00$ \\
\hline 5 & 1 & Aquisição e legalização do veiculo & $18.898,86$ & $18.898,86$ \\
\hline & & SUBTOTAL 1 & & $\mathbf{3 5 0 . 9 3 2 , 8 6}$ \\
\hline
\end{tabular}

Fonte: Elaborada pelos autores (2019)

Os equipamentos consistem em compras do que realmente é necessário em uma pequena agroindústria do setor de Doce Caseiro, sendo detalhado especificamente a seguir na Tabela 3: 
WTIERFACEETECENOĹGGCA

Tabela 3 - Equipamentos/ Utensílios/ Acessórios

\begin{tabular}{|c|c|c|c|c|}
\hline \multicolumn{5}{|c|}{ EQUIPAMENTOS / UTENSILIOS / ACESSÓRIOS } \\
\hline Item & Quant & Descriçao & Valor Unit & Valor total \\
\hline 1 & 1 & Frizzer 1.044 litros, 4 portas & $4.742,07$ & $4.742,07$ \\
\hline 2 & 3 & Balcão Granito - 1,05 x 0,40 & 170,00 & 510,00 \\
\hline 3 & 4 & Tacho Aço 144 litros & 690,00 & $2.760,00$ \\
\hline 4 & 8 & Pá para caldeirão & 70,97 & 567,76 \\
\hline 5 & 1 & Balança Plataforma $150 \mathrm{~kg}$ & 302,00 & 302,00 \\
\hline 6 & 2 & Mesa aço inox $-2,00 \mathrm{~m}$ & $1.844,10$ & $3.688,20$ \\
\hline 7 & 2 & Cuba inox lavatório & $1.007,10$ & $2.014,20$ \\
\hline 8 & 4 & Latão 50 litros & 199,00 & 796,00 \\
\hline 9 & 4 & Caldeirão Industrial 22 litros & 69,99 & 279,96 \\
\hline 10 & 10 & Descascadores & 8,99 & 89,90 \\
\hline 11 & 1 & Datador de potes, tampas e rotolos & 714,66 & 714,66 \\
\hline \multirow[t]{3}{*}{12} & 1 & Bens de Escritório & $5.961,17$ & $5.961,17$ \\
\hline & & SUBTOTAL 2 & & RS $22.425,92$ \\
\hline & & TOTAL INVESTIMENTOS & & R\$ 373.358,78 \\
\hline
\end{tabular}

Fonte: Elaborada pelos autores (2019)

Ao analisarmos as Tabelas 2 e 3, conclui-se que será necessário o valor de R\$ 373.358,78 para o investimento inicial de uma agroindústria de doces.

Os custos fixos foram baseados em pequenas agroindústrias da região do município de atuação. Sendo assim foi feito uma análise em duas pequenas agroindústrias no setor de doce, contatando que a média da energia elétrica fica entre $R \$ 700,00$ reais e $R \$ 870,00$ reais, feito assim uma média de $\mathrm{R} \$ 790,00$ reais mensais.

Segundo o Conselho Nacional de Recursos Hídricos (CNRH) e a Agência Nacional de Águas (ANA, 2019), publica que foi feito um reajuste nos valores das cobranças de água. Os reajustes foram baseados no Índice Nacional de Preços ao Consumidor Amplo (IPCA), apurado pelo Instituto Brasileiro de Geografia e Estatística (IBGE) (ANA, 2019). O valor em $\mathrm{m}^{3}$ da água potável para consumo domiciliar e em pequenas agroindústrias da cidade que vai se estar a pequena agroindústria localizada em Taquaritinga-SP, varia de acordo com o consumo final mensal. Trabalhando com uma base de $85 \mathrm{~m}^{3}$ consumidos mensalmente de água potável, sendo o valor de $\mathrm{R} \$ 6,10$ reais por $\mathrm{m}^{3}$, totalizando $\mathrm{R} \$ 596,50$ reais mensais.

O dimensionamento de mão-de-obra prevê um quadro composto por 3 funcionários diretamente na planta industrial - responsáveis por todos o processo - e um gerente.

Além da mão-de-obra, foram considerados como custos fixos operacionais: Energia elétrica, água, manutenção preventiva e depreciação de equipamentos, conforme apresentados na Tabela 4. 


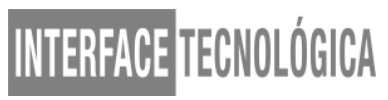

\section{Tabela 04 - Custos Fixos}

\begin{tabular}{c|c|c|c}
\hline \multicolumn{3}{c}{ CUSTOS FIXOS } \\
\hline Item & Descriçao & Valor / mês & Valor / ano \\
\hline 1 & Energia elétrica & 790,00 & $9.480,00$ \\
\hline 2 & Água e esgoto & 596,50 & $7.158,00$ \\
\hline 3 & Mão de obra - Funcionários & $8.294,17$ & $99.530,04$ \\
\hline 4 & Manutenção dos equipamentos & 589,00 & $7.068,00$ \\
\hline 5 & Depreciação dos equipamentos & $1.868,82$ & $22.425,84$ \\
\hline & TOTAL & $\mathbf{R \$ 1 2 . 1 3 8 , 4 9}$ & $\mathbf{R \$ ~ 1 4 5 . 6 6 1 , 8 8}$ \\
\hline
\end{tabular}

Fonte: Elaborado pelos autores (2019)

Os custos variáveis é tudo aquilo que se utiliza para produzir o alimento da agroindústria de doces, sendo apenas as frutas: goiaba, batata-doce, banana, abobora e mamão, e utiliza-se uma média de um quilograma de fruta para a produção de $500 \mathrm{~g}$ de doces. Sendo o açúcar essencial em todos os doces da agroindústria, porém utiliza-se cerca de 0,52 gramas de açúcar para cada 100 gramas de doce produzido.

As embalagens e os rótulos variam, porém, de maneira não significativa no valor final do alimento sendo R $\$ 1,04$ reais para cada doce específico, como a embalagem não se diferencia e sim o rótulo, com valor estimado entre $\mathrm{R} \$ 0,04$ e R $\$ 0,05$. A Tabela 5 específica cada item acima citado:

\section{Tabela 5 - Custos Variáveis}

\begin{tabular}{c|c|c|r|r|r}
\hline \multicolumn{7}{c}{ CUSTOS VARÍÁVEIS } \\
\hline Item & Descriçao & Qtdade / mês & \multicolumn{1}{c}{ Valor unit. } & Valor Total / mês & Valor Total / ano \\
\hline 1 & Açucar - Toneladas & 3,12 & $1.240,00$ & $3.868,80$ & $1.240,00$ \\
\hline 2 & Goiaba - Toneladas & 4,8 & 800,00 & $3.840,00$ & $46.080,00$ \\
\hline 3 & Batata-doce - Toneladas & 2,4 & $1.000,00$ & $2.400,00$ & $28.800,00$ \\
\hline 4 & Banana - Toneladas & 3,6 & $1.490,00$ & $5.364,00$ & $64.368,00$ \\
\hline 5 & Abobora - Toneladas & 3,6 & 750,00 & $2.700,00$ & $32.400,00$ \\
\hline 6 & Mamão - Toneladas & 2,4 & 710,00 & $1.704,00$ & $20.448,00$ \\
\hline 7 & Embalagem - Potes e Tampas & 17.500 & 1,04 & $18.200,00$ & $218.400,00$ \\
\hline 8 & Rotulos em bobinas & 2 & 297,90 & $\mathbf{5 9 5 , 8 0}$ & $\mathbf{7 . 1 4 9 , 6 0}$ \\
\hline & & TOTAL & & RS 38.672,60 & RS 418.885,60 \\
\hline
\end{tabular}

\section{Fonte: Elaborada pelos autores (2019)}

Analisando as Tabelas 4 e 5 é possível constatar que a empresa terá como custos totais anuais $\mathrm{R} \$ 564.547,48$ - resultados da soma de custos fixos e custos variáveis. 


\subsection{Análise financeira}

A análise financeira é tudo aquilo que é dedicado a compreender as finanças do empreendimento, monitorando seus resultados com um bom planejamento. Ajudando a identificar uma possível fraqueza e age para acautelar problemas em curto a longo prazo. Os detalhes obtidos nessa análise ajudam as tomar decisões e a corrigir problemas de dívidas de caixa disponível, tendo um equilíbrio econômico e financeiro, crescimento gradativo e indicadores econômicos favoráveis (SEBRAE).

Os custos de produção unitários de cada sabor foram calculados com base na variação de preço das frutas e demais insumos, além do volume estimado de produção. As estimativas de receitas foram feitas a partir dos valores estimados para venda - preço de venda - atribuídos de acordo com a concorrência da região. Assim:

- Custo do Doce de goiaba é de R\$2,08. Valor de R\$3,74.

- Custo do Doce de batata-doce é de $\mathrm{R} \$ 2,64$. Valor de $\mathrm{R} \$ 4,75$.

- Custo do Doce de banana é de R\$2,77. Valor de R \$4,98.

- Custo do Doce de abobora é de R\$2,03. Valor de R\$3,65.

- Custo do Doce de mamão é de R\$1,99. Valor de R \$3,99.

A Tabela 6 apresenta o cálculo - estimativa - de produção e receita:

Tabela 6 - Estimativa de Produção/Receita

\begin{tabular}{|c|c|c|c|c|c|}
\hline \multicolumn{6}{|c|}{ ESTIMATIVA DE PRODUÇÃO / RECEITA } \\
\hline Item & Descriçao / item & Qtdade / mês & Preço de venda & Receita Mensal & Receita anual \\
\hline 1 & Doce de Goiaba & 4.800 & 3,74 & $17.952,00$ & $215.424,00$ \\
\hline 2 & Doce de Batata-Doce & 2.400 & 4,75 & $11.400,00$ & $136.800,00$ \\
\hline 3 & Doce de Banana & 3.600 & 4,98 & $17.928,00$ & $215.136,00$ \\
\hline 4 & Doce de Abobora & 3.600 & 3,65 & $13.140,00$ & $157.680,00$ \\
\hline \multirow[t]{4}{*}{5} & Doce de Mamão & 2.400 & 3,99 & $9.576,00$ & $114.912,00$ \\
\hline & Total & 16.800 & & & \\
\hline & & & & RS $69.996,00$ & R\$ 839.952,00 \\
\hline & & & RECEITA LÍQUIDA & R\$ $19.184,91$ & R\$ $275.404,52$ \\
\hline
\end{tabular}

Fonte: Elaborada pelos autores (2019) 


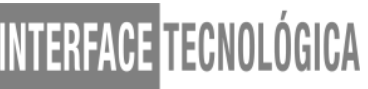

A partir da Tabela 6, foi possível calcular o fluxo de caixa do projeto considerando 3 anos, conforme Tabela 7.

Tabela 7 - Fluxo de Caixa em 3 anos

\begin{tabular}{|c|c|c|c|c|}
\hline & ANO 0 & ANO 1 & ANO 2 & ANO 3 \\
\hline FC SIMPLES & -R $\$ 373.358,78$ & R\$ $275.404,52$ & RS $275.404,52$ & R\$ $275.404,52$ \\
\hline FC ACUMULADO & -R\$373.358,78 & -R\$ $97.954,26$ & $\mathrm{R} \$ 177.450,26$ & $\mathrm{R} \$ 452.854,78$ \\
\hline FC DESCONTADO & $-\mathrm{R} \$ 373.358,78$ & R\$ $245.896,89$ & $\mathrm{R} \$ 219.550,80$ & $\mathrm{R} \$ 196.027,50$ \\
\hline FC ACUM/DESC. & $-\mathrm{R} \$ 373.358,78$ & -R\$ $127.461,89$ & $\mathrm{R} \$ \quad 92.088,91$ & $\mathrm{R} \$ 288.116,41$ \\
\hline
\end{tabular}

Fonte: Elaborada pelos autores (2019)

O projeto apresentou o VPL (Valor Presente Líquido) de R\$288.116,41 em apenas 3 anos de instalações, a TIR (Taxa Interna de Retorno) de 55\% sendo um resultado muito bom, pois foi maior do que a TMA (Taxa Mínima de Atratividade) utilizada (12\%). O payback (Tempo de Retorno do Investimento) do projeto se dará no segundo ano de operação.

\section{CONCLUSÃO}

Ao analisarmos os custos e os indicadores de viabilidade do projeto, os números mostram um satisfatório índice de viabilidade, apresentando uma rentabilidade e um retorno aceitável em apenas 2 anos pagando o seu investimento inicial.

A produção de doces em pote na cidade de Taquaritinga-SP mostra-se promissora, dado as facilidades de distribuição ao mercado consumidor, devido ao fácil acesso a grandes rodovias, fazendo que o produto tenha valor agregado sem grandes custos logísticos. Podemos considerar também a facilidade para adquirir as matérias-primas, já que estamos cercados de fazendas produtoras e acesso a Companhia de Entrepostos e Armazéns Gerais de São Paulo (CEAGESP).

Pela análise dos indicadores econômicos desse projeto, nota-se que a introdução da agroindústria de doces é rentável, devido ao um investimento inicial regular mesmo havendo a construção da unidade fabril, tendo grande público consumidor de doces na região e ao tempo de retorno do investimento relativamente baixo, de acordo com as métricas do projeto. 


\section{REFERÊNCIAS}

ABIA - Associação Brasileira da Indústria de Alimentos, 2017. Disponível em: https://www.abia.org.br/vsn/tmp 2.aspx?id=219. Acesso em: 17 fev. 2020.

AVILA, Rafael; TRÊS INDICADORES DE VIABILIDADE ESSENCIAIS PARA SEU NOVO NEGÓCIO DAR CERTO; 2015. Disponível em: https://blog.luz.vc/o-que-e/3indicadores-de-viabilidade-essenciais-para-seu-novo-negocio-dar-certo/. Acesso em: 20 nov. 2019.

BIAGIO, Luiz Arnaldo; BATOCCHIO, Antonio. Plano de negócios: estratégia para micro e pequenas empresas. 2. ed. Barueri: Manole, 2012.

FILIPIN, Cassandro. Plano de negócio para uma confeitaria de Guaporé/RS. Centro Universitário UNIVATES, 2015. Disponivel em:

https://www.univates.br/bdu/bitstream/10737/853/1/2015CassandroFilipin.pdf. Acesso em: 17 fev. 2020.

GONÇALVES, Vinicius. Fábrica de doces caseiros: como montar passo a passo. Disponível em: https://novonegocio.com.br/. Acesso em: 17 nov. 2019.

KOTLER, Philip. Administração de marketing. 14. ed. São Paulo: Pearson Education do Brasil, 2012.

LONGENECKER, Justin G.; MOORE, Carlos W.; PETTY, J. William; PALICH, Leslie. Administração de pequenas empresas. 13. ed. São Paulo: Cengage Learning, 2011.

SEBRAE. Como fazer uma análise financeira da sua empresa. Disponível em: https://www.sebrae.com.br/sites/PortalSebrae/ufs/pr/artigos/como-fazer-uma-analisefinanceira,d6b1288acc58d510VgnVCM1000004c00210aRCRD. Acesso em: 19 mai. 2020.

SEBRAE. Como montar uma fábrica de doces e geleias. Disponível em: https://www.sebrae.com.br/sites/PortalSebrae/ideias/como-montar-uma-fabrica-de-doces-egeleias,be587a51b9105410VgnVCM1000003b74010aRCRD. Acesso em: 17 fev. 2020.

SENAR. Agroindústria: produção de doces e conservas. SENAR, Brasília, p. 1-122, set./2017.

TORREZAN, Renata. Doce em massa. EMBRAPA. Brasília, p. 1-68, dez./2005.

WESTWOOD, John. O plano de marketing. 3. ed. São Paulo: M. Books do Brasil, 2007. 